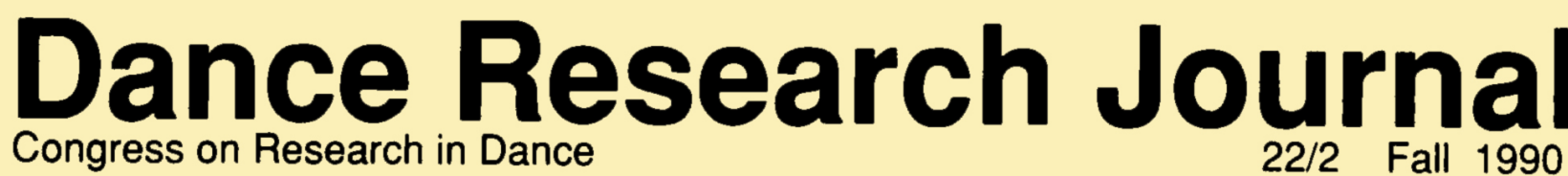

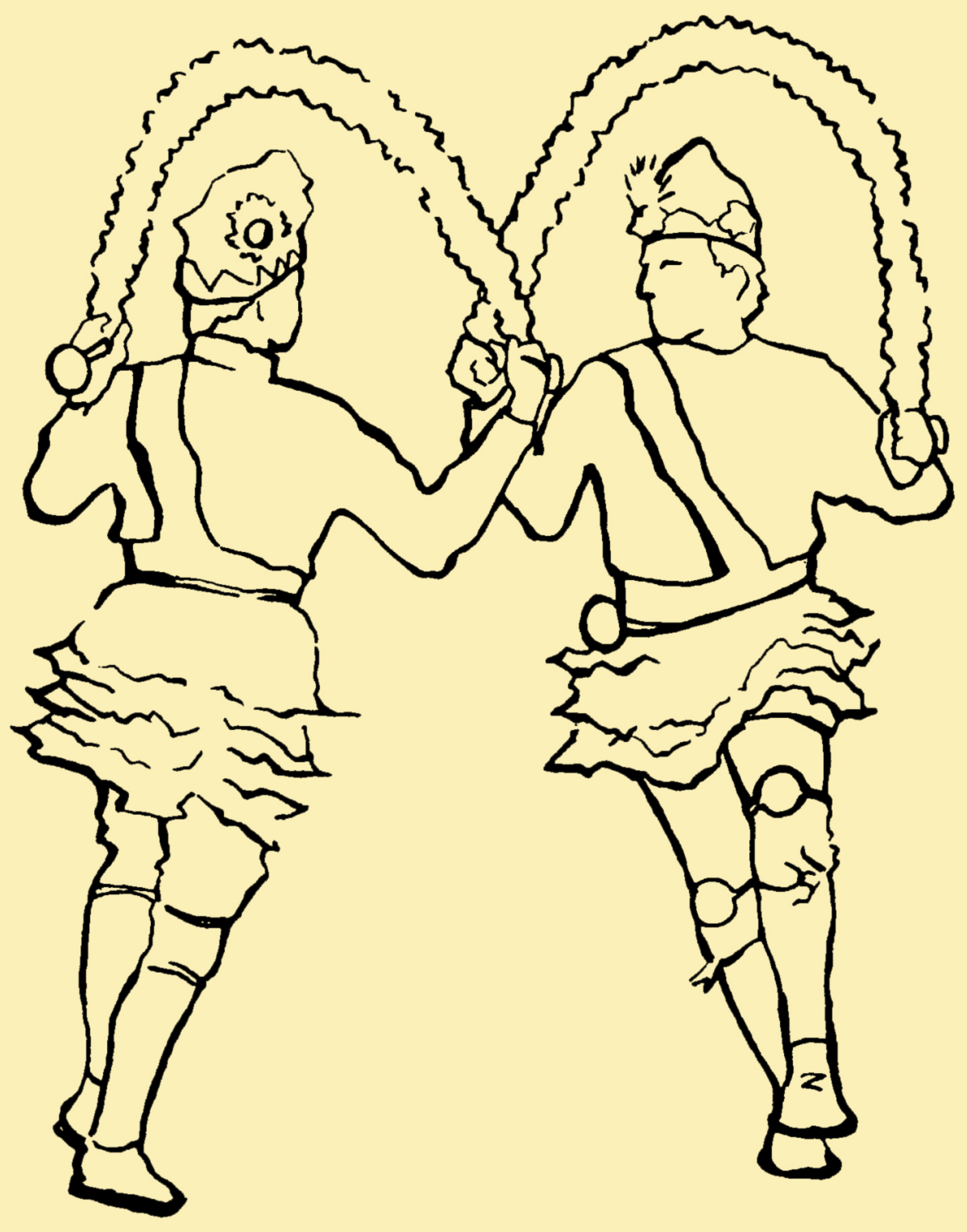


Dance Research Journal, published twice yearly by the Congress on Research in Dance (CORD), carries scholarly articles, book reviews, a list of books and journals received, and reports of scholarly conferences, archives, and other projects of interest to the field. Contributions for publication consideration are open to both members and nonmembers of CORD, and will be accepted at any time.

Views expressed in $D R J$ are the authors', and not necessarily those of the editors, CORD, or CORD officers.

Editor-Judy Van Zile, Department of Theatre and Dance, University of Hawaii, 1770 East-West Rd., Honolulu, HI 96822

Book Review Editor-Linda J. Tomko, Program in Dance, University of California, Riverside, CA 92521.

Editorial Consultants-Carol Bishop (Freelance, England), Rhonda Ryman (University of Waterloo, Canada)

Dance Research Journal is edited and produced at the University of Hawaii and distributed by the New York office of CORD. Membership/subscription information and orders for current or back publications should be directed to CORD, Dance Dept., Educ. 684D, New York University, 35 W. 4th St., New York, NY 10003.

Dance Research Journal is distributed to bookstores in the United States only by Bernhard DeBoer, Inc., 113 E. Centre Street. Nutley, NJ 07110.

Canadian nonmembers and CORD members in Canada who wish to buy extra copies of CORD publications should direct inquiries to Friends of Terpsichore, P.O. Box 563, Postal Station 'Q,' Toronto, Ontario M4T 2N4.

\section{Guide for Contributors}

Articles: $D R J$ is a refereed joumal, using a blind review process. Article manuscripts must be accompanied by written assurance that they have not been published, submitted, or accepted for publication elsewhere. They will not be returned unless accompanied by retum postage.

Manuscripts should contribute original material. They may be research reports, discussions of theory and methods, critical syntheses, or evaluations of the state of knowledge or method in the different disciplines involved in dance research. Articles are evaluated by the Editor and at least two outside readers. The review process is completed as quickly as possible, and every attempt is made to notify authors regarding acceptance within three months. The Editor reserves the right to reject or return for revision any material on the grounds of inappropriate subject matter, quality, or length.

Authors must prepare manuscripts for blind review by putting their name on a separate title page only, and by submitting three clear copies of the manuscript. The entire manuscript, including notes, bibliography, and indented long quotations, should be double spaced. Notes must be numbered consecutively throughout the article and typed on a separate sheet as end notes. Manuscripts, including notes and bibliographies, should follow the Chicago Manual of Style, unless the paper is written in a discipline such as anthropology or biology that follows a different method of footnote style. Illustrative materials, such as tables, maps, and graphic notation, should be done in black ink and should be camera-ready copy. Photographs should have a glossy finish, and authors must obtain permission to publish them if taken by individuals other than themselves. All manuscripts must be accompanied by an abstract of $50-100$ words and bibliographical information of four-six lines that includes current evidence of expertise in the topic of the article.
Manuscripts should be submitted to the $D R J$ editor.

Reviews: Book reviews are assigned by the Book Review Editor, but individuals wishing to review a particular book may submit an inquiry to the Book Review Editor. Reviews in the current issue are the best guide to correct format. The heading should include name of author(s) or editor(s), book title (underlined), place of publication, name of publisher, year of publication, number of pages, cloth or paperbound, and price. Reviews should be scholarly in orientation, and approximately $1500-2000$ words in length. A parallel format should be used for film and other material.

Reports: Reports are assigned by the Editor, but individuals wishing to submit a report on a particular conference or activity are encouraged to submit an inquiry to the Editor. Reports should include what, where, when, who, and how, and should specify the relevance of the activity to dance research. Related literature should be cited, if relevant.

Final Manuscript Approval: Authors of articles will have an opportunity to reread their work after it has been copyedited. The edited manuscript must be returned to the Editor immediately with the author's response to any editorial changes and answers to queries. Galley proofs will be sent during the printing process and should be examined by authors and returned within the specified time.

Complimentary Copies: Contributors of major articles will receive three complimentary copies of the issue in which their article was published; authors of reviews and reports will receive two complimentary copies. 


\section{Dance Research Journal}

Congress on Research in Dance • 22/2 Fall 1990

\section{CONTENTS}

\section{Articles}

Black Faces, Garlands, and Coconuts: Exotic Dances on Street and Stage

Theresa Jill Buckland 1

Voices of Young Women Dance Students: An Interpretive Study of Meaning in Dance

Susan W. Stinson, Donald Blumenfield-Jones, and Jan Van Dyke

The Beseda: The Czech National Dance in Cedar Rapids, Iowa

Helen Chadima

\section{Reviews}

Garafola. DIAGHILEV'S BALLET RUSSES

Claudia Jeschke. .29

Decter. NICHOLAS ROERICH: THE LIFE AND ART OF A RUSSIAN MASTER

Kenneth Archer .31

Redfern. DANCE, ART, AND AESTHETICS

Curtis L. Carter .33

Barker, editor. BOLOSSY KIRALFY, CREATOR OF GREAT MUSICAL SPECTACLES:

AN AUTOBIOGRAPHY

Jenifer Craig

Leslie. A DANCER'S SCRAPBOOK: FROM THE CAPITOL THEATRE, NEW YORK CITY, TO CARNEGIE HALL WITH DORIS NILES

Barbara Barker

BALUNGAN 3, nos. 1, 3; and ASIAN THEATRE JOURNAL 5, nos. 1-2; 6. nos. 1-2

Sally A. Ness 38

Books Received

Journals Received. .42 


\section{Reports}

Society for Dance Research-1989 Meetings

Carol Bishop.

UCLA Dance Ethnology Forum

Kiren E. Ghei

Southern Dance Traditions-Communities in Motion

Chrystelle Trump Bond.

4th World Conference on Folk Dance: Dance-Music in Folk Culture

Selma Jean Cohen

Modes of Inquiry II: Language and Values

Nancy Diers Johnson

International Movement Notation Alliance Conference

Wendy Forster

1990 Laban Research Conference

Madeleine Scott

San Fransisco Performing Arts Library and Museum

Barbara R. Geisler

copyright $\odot 1990$ by the Congress on Research in Dance all rights reserved

ISSN: 01497677

Library of Congress Catalog Card No. 76-12179 